\title{
FRANCISCO DE MIRANDA EN PRAGA, UNA VISITA VENEZOLANA A LA PRAGA DE LA ILUSTRACIÓN, EN 1785. LA PRESENCIA DEL PRÓCER DE LA INDEPENDENCIA EN BOHEMIA
}

Pavel Štěpánek

Universidad Palacký de Olomouc

República Checa

estepanek@tiscali.cz

Resumen. La ponencia trata de la visita del prócer de la Independencia, el venezolano Francisco de Miranda, a Praga, camino a Viena y Budapest, tal como la relata en su Colombeia. No es la única huella de su presencia en Bohemia; tenemos testimonios también de su presencia intelectual, a través de sus libros, ante todo la correspondencia publicada en París en 1793, que está en sendos ejemplares en las bibliotecas palaciegas checas, que indican el interés que ha habido en los escritos de la gesta de la Independencia americana; entre otros, el de Francisco de Miranda, Correspondance Du Général Miranda Avec Le Général Dumourier. París 1793 (Mladá Vožice, nr. inv. 7C 2078, Konopiště, nr. inv. 4-317).

Palabras clave. Miranda. Visita. Praga. Observaciones. Bibliotecas. Colombeia.

Abstract. Francisco de Miranda in Prague, a Venezuelan Visit to the Prague of Illustration, in 1785. The Presence of the Hero of Independence in Bohemia. The paper is a reconstruction of the most important facts of the visit of the predecessor of the Latin American independency, Francisco de Miranda, to Prague, on his way to Vienna and Budapest. The visit of Miranda, related in his monumental book Colombeia, is not the only vestige of the Venezuelan in Bohemia. We have another testimony of his intellectual presence in this country, in his books and correspondence published in Paris in 1793 (Correspondance Du Général Miranda Avec Le Général Dumourier) that we can find in several exemplars in libraries of some palaces and chateaux in Bohemia, for instance, in Mladá Vožice (reg. no. 7C 2078) and Konopiště (reg. no. 4-317).

Keywords. Miranda, Visit, Prague, Observations, Libraries, Colombeia. 


\section{Introducción}

Las relaciones entre la Venezuela colonial y el Reino de Bohemia muestran que su único y exclusivo móvil fue casi exclusivamente religioso, un flujo constante de misioneros desde el viejo continente a América. Ahora, el caso de Francisco de Miranda, prócer de la Independencia, queda como un ejemplo «civil», y además, un reflujo: la visita, en vísperas de la desaparición de la colonia y del surgimiento de un país independiente, hoy Venezuela, de un venezolano a Praga, en 1785.

¿De dónde sacamos la información? Es ante todo gracias a su monumental Colombeia, ese «milagro documental de Venezuela» ${ }^{1}$ que nos permite reconstruir, hasta cierto punto, dicho viaje. Aunque el entonces Reino de Bohemia formaba parte del Imperio austriaco, y Miranda se quedó en Praga solo unos cuantos días, su testimonio es importantísimo por la cantidad de observaciones y por haber registrado algunas realidades que nos ayudan a comprender la época. El original del libro sigue depositado en la Academia de la Historia, en Caracas.

Todos los monumentos visitados o vistos de paso por Miranda merecerían un comentario detallado, valdría la pena buscar las fechas en lo posible exactas acerca de su historia, arquitectos, artífices, etc., según el estado actualizado de conocimientos. O sea, dicho en otras palabras, se trataría de confrontar lo visto por Miranda con lo existente y lo que cada visitante de Praga puede volver a ver, o lo destruido a lo largo del tiempo².

Miranda fue también visitante asiduo de las bibliotecas más importantes de Praga, donde incluso discutió con los intelectuales praguenses los temas políticos de actualidad, incluyendo la independencia de América, tema que le planteó uno de los bibliotecarios y que testimonia gran madurez intelectual más buena información tan lejos de América ${ }^{3}$. En la capital de dicho Reino debió haber, efectivamente, interés por el movimiento independentista de América ya en aquella época y claro, aún años más tarde. Encontramos en sus bibliotecas dos ejemplares de la Correspondencia de Miranda, prócer de la Independencia, con el general Dumourier, publicados apenas un decenio más tarde (París, 1793) ${ }^{4}$.

1 J. L. Salcedo-Bastardo: «Prólogo a Miranda y la senda de Bello», en Castillo Didier (1991: 5). Por otra parte, hoy se está revisando el concepto de la independencia. Se recuerda que el dicho «la conquista la hicieron los indios y la independencia los españoles», Juan Eslava Galán en la entrevista con César Cervera dice: «Los mismos que silenciaron y orillaron a los indios quieren ser ahora sus heraldos» (Cervera; Eslava Galán, 2019). Dicho de otra forma, aplicado a México como caso concreto y bien notable, «los pueblos mexicas subyugados por los aztecas se unieron a Cortés para quitarse de encima la tiranía azteca. Luego serían los criollos, descendientes de los conquistadores y no de los indios, los que encabezaron la independencia contra España». La contribución surgió con el apoyo del Ministerio de Educación, Juventud y Educación Física (MŠMT), grant IGA_FF_2015_025; De la Edad Media a la actualidad. Estudio del arte en los países checos. 2 Štěpánek, Pavel (1994). Miranda en Praga. (La Praga de Miranda). Caracas: Velvyslanectví České republiky. Esta modesta publicación recuerda que es un tema para un gran libro, que podría estar acompañado de numerosas láminas de la época y, posiblemente, del aspecto actual de los monumentos mencionados por Miranda. Se han reducido al mínimo en este estudio los comentarios a los monumentos que aparecen en el citado trabajo publicado en Caracas. Este texto, modificado, aparece también como un capítulo de mi libro Štěpánek, P. (2004). Cruces de la cultura checa y la venezolana. Průsečíky české a venezuelské kultury. Olomouc: Univerzita Palackého, 522 s., 132 il. En esta selección de textos dejo aparte sus notas sobre las historias militares, que son un tema independiente y diferente.

3 En su libro Lugar de crónicas. Academia Nacional de la Historia. Serie «El Libro Menor», Caracas 1985, Denzil Romero, concretamente en el capítulo El Señor Plicka (p. 101-104), explica que a este emigrante checo residente en Venezuela se le hizo familiar el ambiente mágico de Praga y Bohemia. El autor me lo volvió a contar con una prolijidad de detalles que no pueden caber en este trabajo sumario.

4 Uno se guarda en el Palacio de Mladá Vožice, otro en el de Konopiště. Evidentemente, el interés político perdura a lo largo del siglo XIX, pues en otro palacio, el de Klášterec, se encuentra una selección de escritos de Simón Bolívar en alemán con el retrato grabado de Bolívar como «Dictator von Columbia» (Bibliothek 
El prócer de la independencia de Venezuela, el general Francisco de Miranda, viajó por toda Europa recorriendo también los países del Reino de Bohemia desde Sajonia hasta la ciudad fronteriza de Znojmo. Dedicó una atención especial de su estancia en Praga en 1785, donde desarrolló asimismo una rica vida social. Este texto presta atención ante todo a sus visitas de los monumentos más importantes en Praga, y al mismo tiempo presta atención de sus fugaces pero aclaradoras observaciones a las artes plásticas. Así, confrontando con la literatura de la época, he podido identificar el tríptico por él descrito como el de Tomasso da Modena del castillo de Karlštejn, a la sazón expuesto en la biblioteca de Klementinum, de Praga, y al que Miranda prestó atención, junto con unos cuadros calificados como españoles.

Una de las aventuras culturales e intelectuales más importantes que ha emprendido un venezolano es la del prócer de la Independencia al realizar, entre otras cosas, el archifamoso viaje a Europa, cuya constancia dejó en su Colombeia ${ }^{5}$. Son sesenta y tres volúmenes encuadernados por el mismo Miranda, que contienen íntegra su historia y el acervo de textos correspondientes al trabajo y la vida de cuatro decenios. Durante cuatro años, de 1785 a 1789, deja constancia, cada día, de lo que recorrió, vivió y vio, discutió y consultó. Así dejó «tal vez la más completa información sobre el Siglo de las Luces, hasta merecer ser considerado "el mayor memoralista de su tiempo"» (Salcedo-Bastardo, 1988: 939-944). Este diario minucioso de sus impresiones y observaciones es una fuente inagotable para abordar el pensamiento de Miranda desde los ángulos más diversos. Su agudeza de observación de los monumentos arquitectónicos y artísticos le ha situado también en el puesto del prócer de la crítica de arte no solo en Venezuela, sino en toda América (Pineda, 1986: 9) ${ }^{6}$.

Sin embargo, al comentarse ese recorrido europeo, a veces ni siquiera se recuerda la parte que para nosotros es la más importante: la visita de Miranda a Praga, atravesando el Reino de Bohemia, la actual República Checa, que entonces formaba parte del Imperio austriaco, al viajar desde Sajonia a Viena ${ }^{7}$. Aunque Miranda se quedó en Praga solo unos días, mientras que en Rusia o Grecia, por ejemplo, meses, su testimonio del viaje en 1785 es importantísimo por la increíble cantidad de observaciones, por más breves que fuesen, y por haber registrado algunas realidades que nos ayudan a comprender la época en general. Es el único caraqueño y con plena justificación podemos decir venezolano, pues ocho años antes, en 1777, una Real Cédula creó la Capitanía General de Venezuela, fecha desde la cual la palabra Venezuela significó, como había apuntado Mariano Picón Salas (1975: 69-70),

la fusión de núcleos territoriales que vivieron dispersos y que con la Guerra de Independencia adquirieron la más valedera unidad histórica [...] De no haber dejado Miranda las pruebas escritas en cuanto vio y experimentó, la posteridad no habría creído ni imaginado siquiera el colosal alcance de su peripecia vital, la vastedad grandiosa de sus temas, la ponderación de sus juicios, la sutileza de

parlamentarischer Berdsamkeit oder..., Leipzig 1833). Este grabado, con el mismo letrero, está en las colecciones de la Galería Nacional de Praga. De Andrés Bello solo hay una Gramática de la lengua castellana destinada al uso de los Americanos, ya tardía (París, 1908), en el Museo Nacional de Praga.

5 Miranda (1981). Prólogo, notas y cronología de Josefina Rodríguez de Alonso. Agradezco a la Academia de la Historia de Venezuela por haberme facilitado el estudio del original.

6 Sobre las nuevas ediciones del Diario de Miranda véase Lovera de Sola (1994); LOVERA DE SOLA, R. J. (1994). «El “Diario" de Francisco Miranda». Diario de Caracas, 6-4-1994.

7 Así, por ejemplo, Uslar Pietri (1981: 41) enumera muchos lugares visitados por Miranda, excepto precisamente Praga. A su vez, incluso autores tan serios como Robertson (1982: 57), presta atención únicamente a la visita de Miranda en Praga a un burdel. La única excepción a la regla es el libro de Rodríguez de Alonso (1974) que dedica un capítulo a La ville de Rodolphe et de Jean Huss (pp. 147-150). 
su espíritu y el hilo conductor seguro, incuestionable, constante, obsesivo de su vivir: la búsqueda de la libertad ${ }^{8}$.

\section{Praga vista por Miranda}

Miranda visitó Praga en un momento de cambio y de transición de dos épocas, la barroca y la ilustrada, entre las reformas del Emperador José II y el estallido de la revolución francesa, en la cual el ilustre visitante de la capital del Reino de Bohemia participaría más tarde. El paso de las épocas se nota en algunos de sus comentarios, como veremos.

Parece que Miranda, siendo un hombre plenamente entregado a los ideales neoclásicos de la Ilustración (con todo su racionalismo simplificado), como lo testimonia también su interés por Grecia, su literatura y arte, a lo cual contradice la Praga barroca. Lo testimonia, entre otras cosas, su repetida mención, más bien negativa, acerca del puente Carlos. Hay que tener en cuenta que en la etapa praguense es su compañero de viaje inglés, Smith, enemigo abierto del catolicismo, quien hace apuntes para Miranda, cosa que puede haber influido en la formulación ${ }^{9}$.

El propósito de este trabajo es aproximar visualmente lo que había visto Miranda en Praga, y de lo que dejó constancia en su impresionante Colombeia ${ }^{10}$, así como ofrecer sugerencias para reconstruir el recorrido de la Praga que vio Miranda y que, afortunadamente, en muchas partes, queda perfectamente conservada, sin huellas del paso del tiempo o con mínimos cambios. Aunque no todos los lugares son mencionados, es cierto que Miranda, peregrino incansable, habría recorrido todo el actual centro histórico.

Esperemos que este repetir la memoria, el deambular del Generalísimo por la Praga de las Luces, aunque con muchas sombras, sea revivido en la memoria, a través de las imágenes de los grabados de la época. Los monumentos visitados o vistos por Miranda no se comentan aquí con detalles acerca de su historia, arquitectos, artífices, fechas, etc., según el estado actualizado de conocimientos, pues ya fueron objeto de tal análisis. Puede suponerse también que había podido mandar los libros y grabados adquiridos a su residencia en París o Londres. Dicho de otro modo, se trata de confrontar lo visto por Miranda con lo existente y lo que cada visitante de Praga puede volver a ver y apreciar a través de los grabados de la época o personalmente, como testigo ocular cuando vaya a la actual capital de la República Checa. Incluso podemos pensar que Miranda se haya llevado algunos grabados, como los de la serie de vistas publicadas este mismo año por Josef Carmine, o antes, entre 1781 y 1783, la serie de seis vistas del Puente Carlos y las plazas de Praga, grabados por Jan Balzer, de Praga."

8 Su viaje es absolutamente insólito entre los venezolanos de la época. Otro gran viajero de la época, el geógrafo italiano que trabajó en Venezuela, Agustín Codazzi (1793-1859), aunque viaja bastante cerca del Reino de Bohemia -durante su viaje de Valaquia a Polonia- no pasa ni siquiera por la Alta Hungría, la actual Eslovaquia.

9 Archivo del General Miranda/Viajes/Diarios/1750-1785/. Tomo I. Editorial Sur-América, Caracas 1925, transcribe el texto original inglés (pp. 414-442). Comparando el original que se me permitió estudiar en La Academia Nacional de la Historia, pude comprobar algunas ligeras diferencias de la transcripción que aquí advierto: el bibliotecario Bertolotti figura en el original como Bartolotti, Belvedere / Belvidere, etc. A veces hay dualidad de transcripción como Collin / Kollín, o evidentes faltas de ortografía, desconocida por Smith y Miranda, como Bomischbod (en vez de Boehmischbrod), Iglau / Jihlava transcribe a la inglesa Iglaw, etc.

10 Castillo Didier (1991: 111) en el capítulo titulado El Milagro Documental de América señala que su epopeya de viaje -Colombeia- tenía como modelo la Odisea y personalmente, la figura de Ulyses.

11 Según la amable comunicación del exdirector del Museo de la Capital de Praga, el Dr. Zdeněk Mika, Miranda, como cualquier visitante de Praga, pudo haber adquirido grabados en cualquier librería o taller de grabado. Hay grabados que aparecieron poco antes de la visita de Miranda, según la lista publicada en Pražský sborník (Miscelánea praguense). Praga 1967, N 12, pp. 175-179. Existen grabados publicados antes de 


\title{
3. La Praga de Miranda: volviendo a leer su Colombeia
}

El primer autor checo en prestar atención a la descripción de Praga por Miranda fue Josef Polišenský; sin embargo, fue muy breve al presentar el tema ${ }^{12}$. Nos informa acerca de la ruta de Francisco de Miranda y su amigo y compañero el coronel William Stephen Smith, ex-secretario de la Embajada Americana en Londres y exadjunto de Washington ${ }^{13}$.

Vamos a aprovechar sus palabras para resumir, entonces, el tema que vamos a tratar con mayor detalle:

\begin{abstract}
Ambos viajeros, seguidos por las autoridades españolas que intentaron detener a Miranda, ya antes condenado a la cárcel por diez años, partieron desde Inglaterra a través de los Países Bajos y la Alemania del Norte para Prusia, donde en las afueras de Berlín observaron el último ejercicio otoñal de las fuerzas armadas prusianas, dirigidas personalmente todavía por Federico II. En vez de regresar a Londres vía París (donde esperaba a Miranda una orden de arresto), partieron a Sajonia, visitaron Leipzig y Dresde. De ahí se fueron para Bohemia, el 7 de octubre 1785 y [...] pudieron llegar a Praga ya el 9 del mes mencionado. Al día siguiente empezaron con la visita de la ciudad: visitaron en primer lugar el Castillo de Praga y la catedral de San Vito. El protestante Smith (autor de hecho del diario) no tenía sensibilidad para las estatuas del Puente de Carlos y los vestigios de la fe católica que le fue ajena, ante todo después de visitar la Capilla de Belén y después de las consideraciones sobre Juan Hus. Otro día visitaron la «biblioteca imperial» en el Clementinum, es decir, la Biblioteca Universitaria de hoy, donde acompañados del Señor Bertolotti -para el cual tenían una recomendación de parte del abate Grüber, capellán de la Embajada Imperial en Berlín- visitaron las salas, adornadas presumiblemente con cuadros españoles y manuscritos, incluyendo Reglamentos Militares en latín de Jan Žižka de Trocnov por los que -como militares- manifestaron su interés. Bertolotti les recomendó aún la visita de la Biblioteca de Strahov, donde «uno de los hombres más cultos que en su vida encontraron» les mostró una capilla [...] decorada con mármol y con un órgano que tocó para ellos un organista. En la sala principal de la biblioteca [...] admiraron los frescos de Siard Nosecky y unos 50000 libros. El 11 de octubre, probablemente por la tarde, abandonaron Praga para visitar el campo de batalla cerca de Kolín.
\end{abstract}

Este es, en breve, el resumen y para nosotros el plan de viaje que vamos a seguir con mayor detalle (Polišenský, 1988: 80). Nos apoyaremos en la última edición de Colombeia (1981), concretamente en el capítulo Territorios del Santo Imperio Romano Germánico. Diario de Praga, Viena, Esterházy y Trieste. Camino de Praga, 1875 (Miranda, 1981: 135-143). Prefiero poner primero siempre el nombre del autor, Miranda, seguido de la fecha del calendario, acompañándolo de una nota, en la que se da la página exacta, de modo que resultará facilísimo orientarse en la lectura de Colombeia.

Ahora nos detenemos en los puntos principales del itinerario de Miranda en su viaje de Dresde a Praga, tal como dictó sus observaciones a su secretario Smith (quien, naturalmente, pudo haber cambiado las palabras de Miranda incluido en las formulaciones). Así, Miranda, 7 de octubre de 1785 (Miranda, 1981: 133):

la gira de Miranda. En este caso se consulta la edición en facsímil: Prague architecture in End-of-18th-Century Engravings. Idea y texto de Jarmila Lakosilová y Jana Pasáková, publicados por Škodaexport, Foreign Trade Corporation, Praga, sin fecha. Los grabados inmediatamente anteriores al viaje de Miranda son los de Josef Carmine, quien grabó en cobre seis vistas de Praga hacia 1780, publicados en Augsburgo, entonces un importante centro de grabado.

12 Polišenský (1976a: 326-327); Polišenský (1988: 79), al comentar la estancia de Miranda en Praga, también aprovecha el libro de Grigulievich (1974) y el trabajo de Mayo (1965).

13 Polišenský (1976b: 214) califica el capítulo del libro de Josefina Rodríguez de «bastante sorprendente». 
A las seis de la mañana del día 7 dejamos Dresde, pasamos Pirna y entramos en las montañas que separan Sajonia de Bohemia [...] Después de haber pasado la frontera de Bohemia alrededor de las 10 a. m. y de viajar todo el día a través de montañas y por una carretera mala, paralela al Elba (río Labe), nos alojamos a las diez de la noche en Lobositz (Lovosice). [...] Cambiamos caballos en Zehisi ${ }^{14}$, Peterswald (Petrovice o Petrský vrch), Aussig (Ústí) y Lobositz. Las diversas pequeñas aldeas que pasamos son pobres; están protegidas por crucifijos e imágenes y son muy distintas a sus vecinos los sajones, a pesar de que la religión es la misma. ${ }^{15}$

Miranda, 8 de octubre (Miranda, 1981: 133):

El día 8, acompañados por el maestro de escuela y por una anciana como intérprete, practicamos un reconocimiento del campo de batalla donde Federico, con 24000 prusianos, atacó el 2 de octubre de 1756 el campamento austriaco de 60000 hombres, bajo el mando del Mariscal Browne. [...] De aquí pasamos las aldeas de Budyne, Beltrusy (Veltrusy) y Sdiby (Zdiby). El campo es bonito, con una buena carretera y llegamos a las diez a Praga, la capital y residencia del Rey de Bohemia. ${ }^{16}$

Al entrar en Praga, la Colombeia, por boca de Miranda y pluma de Smith, hace más frecuentes menciones estéticas y sociales de todo tipo que nos permiten apreciar sus pasos por la capital de Bohemia. Aquí de veras vale la pena prestar atención a cada detalle que expresa o veladamente alude al entorno de la capital del Reino de Bohemia, su ambiente cultural, intelectual y expresamente artístico. Se deja para otra oportunidad lo militar. Y vemos que no pasa por alto ningún campo de batalla en las cercanías de la ruta, que incluso somete a la necesidad de ver los lugares de las batallas más importantes.

Miranda, 9 de octubre, domingo (Miranda, 1981: 135):

Asistimos al culto en la catedral principal y en la capilla del palacio; la primera es un vasto y elegante edificio, ricamente adornado, la segunda es de arquitectura gótica y al interior es más bien bonita que elegante. Entre los escudos que la adornan están las armas de España, etc., etc. ${ }^{17}$ (cont.)

Miranda, 9 de octubre (cont.) (Miranda, 1981: 135):

14 Zehisi -locación identificada, mencionada incluso en otros escritos, por ejemplo: Reich and Austrian invasion of Saxony- http://www.kronoskaf.com/syw/index.php?title=1759_-_Reich_and_Austrian_ invasion_of_Saxony.

15 Los crucifijos y las imágenes que Miranda menciona son aún un signo distintivo del urbanismo campesino de Bohemia y del catolicismo imperante en el país hasta hace poco. El historiador Zdeněk Kalista en el libro České baroko, Praha: ELK 1941 habla, en más de una ocasión, de la espiritualización del país. Podemos suponer que Miranda habrá buscado el lugar en que ocurrió la batalla de Lovosice entre Federico II de Prusia con los ejércitos austriacos del mariscal Brown el día 1 de octubre de 1756 que estuvieron acampados cerca de la localidad de Budyně nad Ohří. Los ejércitos aliados de Austria y Sajonia al final se rindieron.

16 Budyne / Budyně nad Ohř́; allí vivió durante un tiempo Tycho de Brahe.

17 El doble etcétera indica que Miranda ha recorrido toda la catedral, limitándose a señalar lo que le parecía lo más importante. Como está dentro del recinto del Castillo de Praga, también hubo de recorrer el Palacio Real, cuya configuración definitiva data de poco tiempo antes de la llegada de Miranda (hacia 1774), siendo obra del arquitecto Nicola Pacassi. La capilla a la que se refiere puede ser tanto la capilla de San Wenceslao como la de Todos los Santos, contigua a la sala Wladislao, y adaptada en 1730. Sin embargo, dado que habla de los escudos de España, debe ser el presbiterio de la Catedral de San Vito, entonces sin la ampliación posterior, de modo que puede entenderse la palabra «capilla», sobre todo si pensamos en la tradición española que designa como capilla mayor precisamente esta parte de la catedral. 
Desde lo alto del palacio, hay una vista muy completa de la ciudad que está construida sobre la ladera de una colina muy pendiente, que forma la ribera de Moldava (río Vltava), sobre el cual hay un puente de piedra que une la ciudad antigua con la nueva. Aquí hay tres colegios e iglesias de los jesuitas, muy elegantes y muy caros. La casa del obispo, a la derecha del palacio, está bien proporcionada y bien situada. [...] En todo cruce de camino hay una imagen o un crucifijo, ante el cual los paseantes se arrodillan y lo besan y los que van a caballo se quitan el sombrero y se persignan..$^{18}$ (cont.)

Miranda, 9 de octubre (cont.) (Miranda, 1981: 135):

El campo en general está bien cultivado, pero el aspecto de las aldeas y de los habitantes prueba que trabajan para otros. Cerca de cada ciudad hay una casa grande bien construida, en la cual el encargado de la Administración del pueblo es mantenido por los que trabajan. Después de los oficios visitamos las fortificaciones; no hay ni una sola parte de ellas que no esté dominada por los montes colindantes [...] Nos encontramos con el General Duportal con sus ordenanzas en el Puente. Comimos en casa. Tuvimos música y fuimos al teatro. Es grande, una platea muy cómoda, 94 filas de palcos; es el más proporcionado de los que he visto hasta ahora. A la plataforma le faltan adornos, si no, estaría completa. ${ }^{19}$

\section{Miranda, 10 de octubre (Miranda, 1981: 136):}

Visitamos la biblioteca establecida por los jesuitas, pero denominada ahora Biblioteca Imperial. Está bien dispuesta en apartamentos elegantes y contienen 100.000 volúmenes. Hay aquí una esfera celestial, que por medio de una máquina de precisión cuenta con exactitud las revoluciones de los cielos y también un aparato eléctrico muy bueno, diseñado y fabricado por el Señor Unger, el superintendente de este colegio. Nos atendió con gran cortesía el Señor Bertolotti, bibliotecario. Vimos dos cuadros pintados en el siglo XIV, durante el reinado de Carlos IV, que muestran solo el estilo de los retratos de la época. ${ }^{20}$ (cont.)

18 Miranda se refiere a la vista que se ofrece desde el Palacio Real, primero de Malá Strana (El Barrio Pequeño), luego de Staré Město (Ciudad Vieja), y finalmente, la Nové Město (Ciudad Nueva) de Praga. Parece que cuando, al hablar del puente, llamado entonces de Piedra, hoy Carlos («puente [...] que une la ciudad antigua con la nueva») ... parece que confunde La Ciudad Nueva con Malá Strana. Los tres colegios e iglesias de jesuitas son la iglesia de San Nicolás de Malá Strana, la de San Salvador y el de San Ignacio, con sus respectivos colegios. La casa del obispo es el actual Palacio Arzobispal, construido veinte años antes de la visita de Miranda por el arq. J. J. Wirch.

19 Se trata del Teatro Nostitz, por haber sido el conde Nostitz-Rieneck el comitente de la obra, comprado más tarde (1799) por los Estados de Bohemia y llamado Teatro de los Estamentos (también), hoy Teatro Tyl (Tylovo divadlo), terminado dos años antes de la visita de Miranda en Praga. Se estrenó para el público el día 21 de abril de 1783, con la obra Emilia Galotti, de Lessing. En 1787, o sea, dos años después de la visita de Miranda, se estrenó aquí Don Juan, de Mozart. El nombre actual se debe a Josef Kajetán Tyl, autor de la pieza Fidlovačka, en la cual se oyó la primera vez la melodía y el texto del actual Himno Nacional Checo.

20 La biblioteca de los jesuitas, Biblioteca Imperial, hoy, Biblioteca Universitaria y Nacional, en el edificio de Klementinum (de San Clemente), de la Ciudad Vieja de Praga. Miranda la vió aún en su esplendor, aunque ya tras la abolición de la Orden Jesuita. Fue renovada como biblioteca de Estado (Imperial) en 1777, con un total de 50.000 volúmenes. En 1780 fue nombrado el primer bibliotecario oficial, Karl Rafael Ungar, monje premonstratense, profesor del seminario arzobispal, decano y rector de la Facultad de Filosofía de la Universidad de Praga, de nacionalidad alemana. Nació el 12 de abril de 1743 en Žatec, murió en Praga el 14 de julio de 1807 en Praga. Desde 1768 doctor en filología, desde 1769 bachiller de las Sagradas Escrituras, desde 1770 sacerdote. En 1780 nombrado bibliotecario-director, cargo que cumplió hasta su muerte. Sus retratos se guardan en la Biblioteca Nacional hasta hoy. Véase Voit (1990: repr. 126 y 128). Otra versión del grabado en Blažek (1937: 27). Un año antes de la visita de Miranda surge la Sociedad Erudita de Bohemia, antecedente de la Real Sociedad de Ciencias de Bohemia, con la cual Ungar colaboró estrechamente. También fue miembro de la logia masónica; dado que Miranda fue masón de alta logia, se habrían entendido bien. Ungar publicó un 
Los mencionados dos cuadros que Miranda vio pueden identificarse gracias a otro relato de la época. ${ }^{21}$

\section{Miranda, 10 de octubre ${ }^{22}$ (Miranda, 1981: 136):}

Visitamos el antiguo ayuntamiento. Prestamos nuestros respetos al Gobernador y asistimos a la revista de las tropas, soldados bien vestidos, de blanco con abrigos cortos, puños bordados y capas, una gorra de acero dada vuelta delante y pequeña visera de latón. Visitamos sus cuarteles, están bien alojados, dos en cada cama y reciben dos groties por día. Son hombres sanos y ordenados y en general jóvenes. La visera tiene una protección contra el destello. (cont.)

\section{Miranda, 10 de octubre (cont.) (Miranda, 1981: 137)23:}

Pasamos a las colinas que están delante de la ciudad nueva. Dominan perfectamente las fortificaciones y muestran claramente el derroche de dinero que se hizo en su construcción. Fueron atacadas furiosamente por los franceses en 1742 y bombardeadas por el Rey de Prusia...

\section{Miranda, 10 de octubre (cont.) (Miranda, 1981: 137) ${ }^{24}$ :}

Regresamos a la biblioteca, donde el Señor Bertolotti nos enseñó varios libros viejos españoles del s. XV y el extraordinario manuscrito original de Joannis Zizka titulado «Constitutio Militatum

manuscrito del jesuita Bohuslav Balbín-Bohemia docta, y la primera bibliografía retrospectiva dela producción literaria checa Allgemeine Boehmische Bibliothek (1786). Ungar fue el que tuvo que clasificar los libros que llegaban de otras bibliotecas jesuitas confiscadas de todo el país. Antes de morir Ungar, en 1807, la biblioteca creció en 140.000 volúmenes. También se hizo obligatoria la costumbre de que los editores enviaran a la Biblioteca un volumen obligatorio de cada edición. Cada día la visitaban 300 lectores. Véase Voit (1990: 83-89).

21 Probablemente por August Gottlieb Meissner, pues aparece como anónima: Beobachtungen in und über Prag von einem Reisenden Auslander. II, Praha 1787, p. 5. Agradezco la transcripción al prof. Vít Vlnas: «In dem ersten Lesenzimmer haengen zwey Oelgemahlde, die aus dem 14-em Jahrhunederte sind, da man hoch sonst allgemein den Aufgang dieser Kunst in das 15te Jahrhundertsezt. Das eine stellt eine Maria mit dem Kinde vor. Das Kolorit is von Mutina. Das andere is ein Darstellung ist matt. Es is von Mutina. Das andere ist ein groesseres Stueck, hat zar sehr starke Zuege, aber es herrscht ein Ausdruck darin, der von Werthe des Künstlers zeuget». El interés que notamos por la técnica de la pintura forma parte de la discusión que se desarolló en los círculos eruditos de Praga al filo de los siglos XVIII y XIX, y que parten de la convicción - de raíz académica neoclásica - de que el rendimiento artístico consiste en la dominación soberana de los problemas técnicos. Resulta claro que los problemas de estilo quedaban aún fuera de su alcance. Véase Dvořáková (1986: 45). Identificar, por otra parte, las obras, sobre las cuales escribe más tarde Hegel (1824) resulta imposible, pues sus opiniones sobre arte son muy vagas y generales, y el filósofo incluía todas las obras, checas, flamencas, holandesas en la «vieja escuela alemana». Lo decisivo es, sin embargo, que a la sazón ya no estaban las dos obras en Clementinum, sino devueltas al Castillo Karlstejn. Véase también Polišenský (1988: 119-120), donde leemos el testimonio del poeta alemán: «... Aber was ich geschen-inbesondere da gelehrte altdeutsche Leckerbissen netrifft, - Dir zu beschreiben, Hauptsachen waren hier zwei altdeutsche Bildern...». Toda la bibliografía en torno al cuadro de Tomaso de Modena que vio Miranda, véase Pujmanová (1987: 148-153), n 94 (cat. ed. O. Pujmanová). Publiqué La Virgen con el Niño como contraportada en el libro Štěpánek (1994).

22 Se trata del Ayuntamiento de la Ciudad Vieja. Durante el viaje de Miranda se hacían, entre 1784-1787 grandes trabajos en el interior, reconstruyéndose espacios renacentistas por el arquitecto M. Hummel, pero poco ha llegado hasta nosotros.

23 Aquí Miranda se refiere a las fortificaciones en la colina de Vyšehrad, lugar ligado a las leyendas checas, pero a la sazón una importante citadela de Praga que defendía la capital del sur. La última puerta fue construida en 1742 durante la ocupación francesa por el arquitecto Berdiquier. Sin embargo, Miranda también pudo ver los bastiones que hasta ahora se conservan en las inmediaciones del monasterio Strahov.

24 El manuscrito Constitutio Militatum Confaedetratum anno 1423 lleva una fecha contradictoria y el haber identificado una de las personas como Luther quien aparece en la escena mucho más tarde, muestra que o se trata de un manuscrito más tardío (cien años), o se ha confundido la identidad de los personajes descritos. 
Confaedetratum anno 1423». Es un viejo manuscrito de la época de la revolución; el margen está adornado con pinturas emblemáticas de su contenido. En una hoja están los bustos de los tres personajes principales que produjeron la revolución de los principios religiosos que despertaron a la humanidad de aquel estado de inactividad estúpida que el fanatismo y la superstición no fallan nunca en imponer. Wyclif, de Oxford, está representado haciendo fuego con el pedernal, Juan $\mathrm{Hu}^{25}$ enciende una vela con la chispa y el famoso Lutero ${ }^{26}$ anda con paso majestuoso llevando una antorcha flameante. (cont.)

\section{Miranda, 10 de octubre (cont.) (Miranda, 1981: 138) ${ }^{27}$ :}

En el famoso puente hay unas treinta estatuas de santos de cuerpo entero, y un crucifijo de bronce, y toda colina y cruce de caminos está arreglado para apoyar el sistema de la iglesia.

Miranda, 10 de octubre (cont.) (Miranda, 1981: 138) ${ }^{28}$ :

De aquí fuimos a la iglesia de Bethlem, donde el famoso Huss atacó por primera vez los principios de la religión cristiana; es de antigua arquitectura gótica y tiene una gran pila consagrada. Aún le quedan bastantes cuadros buenos e imágenes. (cont.)

Miranda, 10 de octubre (cont.) (Miranda, 1981: 138) ${ }^{29}$ :

Visitamos la biblioteca de Strahow, de los Premostratenses, que es una institución de unos 107 monjes, muy bien situada sobre una altura al norte de la ciudad, desde la cual domina una amplia vista; tiene jardines grandes y es en realidad un palacio. Aquí viven a cuerpo de rey, y gente de todas las categorías los tratan con respeto. Son, en verdad, las personas más corteses que hayamos encontrado. Esta biblioteca, bien distribuida en una vasta sala, es bien proporcionada y decorada con frescos por un monje llamado Nosetkseki (sic, debe decir Nose(t)cky) y contiene 50.000 volúmenes para el uso del convento). Un monje complaciente y agradable nos llevó a la capilla, cuyos soberbios altares son de bellísimo mármol y las columnas también. Los cuadros son buenos igualmente y se enorgullece de poseer un órgano, considerado el mejor de este reino, y de acuerdo con su tamaño, el mejor de Europa [...] Su sonido es suave y agradable y cuando eleva el tono, ofrece mayor sonoridad que cualquier instrumento que haya oído nunca ${ }^{30}$.

Debo observar que el bibliotecario, el Señor Bertolotti, en nuestra segunda visita, al enterarse de que éramos americanos habló con viva admiración de nuestra revolución y dijo que se había

25 Sobre Hus véase Luis Alberto Ruiz (1977: 138).

26 Sobre Lutero véase Luis Alberto Ruiz (1977: 175).

27 El famoso puente es el «de Piedra», más tarde llamado de Carlos, con 32 esculturas (2 en cada uno de los 16 arcos). Se siente el resentimiento de Miranda frente a la Iglesia Católica.

28 La capilla de Belén fue derribada el año 1786, poco después de que la visitara Miranda, pues desde 1661 la poseían los jesuitas. Parece que fuera uno de los últimos visitantes extranjeros que la viera en su estado original. Por razones ideológicas fue reconstruida entre 1950 y 1952 por el régimen comunista para debilitar así la imagen de la Iglesia Católica.

29 El monasterio de Strahov - la Real Canonjía de los Premonstratenses - de la orden de San Norberto fue fundado en 1140. Muy poco antes de la llegada de Miranda (entre 1782-83) fue construida, pero aún no pintada, la segunda biblioteca del monasterio, la Sala Filosófica (se estaba decorando aún en 1794 por el pintor vienés Franz Anton Maulpertsch y su taller), pero como Miranda menciona las pinturas de Nosecký, será en la primera, construida por Domenico Orsi (?) entre 1671-79, la Sala Teológica, decorada por el miembro de la misma Siard Nosecký (1693-1753), donde habría ocurrido el encuentro y la conversación descritos por Miranda entre Bertolotti y él.

30 ¿Habrá sido Jan Lohelius Oehlschlaegel (1724-88), el magnífico organista y compositor que habrá tocado el órgano en el momento en que Miranda estuvo? Sobre el personaje, véase Československý hudební slovník osob a institucí I., Praga 1963, p. 126. 
convencido [...] como amigo de la felicidad de la humanidad, de acuerdo con las circunstancias [...] que la libertad era la nodriza de la ciencia y la única situación bajo la cual podían florecer las sociedades. Da al pueblo rienda suelta y tolerancia, y la mente humana se amplía y la felicidad de la sociedad aumenta rápidamente. Cuando nos despedimos, nos dio su bendición y oraciones por nuestro éxito, cuyos efectos -dijo- sentía vibrar a orilla del Moldava (río Vltava). Me da una gran satisfacción de oír a los letrados de este país tan interesados por nuestra felicidad y éxito. (cont.)

Miranda, 10 de octubre (cont.) (Miranda, 1981: 139) ${ }^{31}$ :

El Belvedere es un conocido lugar de bastante gusto que domina una vista extensa. Esta ciudad está agradablemente situada sobre ambas márgenes del Moldava (el río Vltava), llamadas antigua y nueva ciudad, unidas por un puente muy grande, adornado o más bien sobrecargado con más de cien imágenes.

Luego, Miranda sigue viajando por Bohemia y Moravia hacia Viena; Miranda, 11 de octubre (Miranda, 1981: 140-141) $)^{32}$ :

Salimos [...] con el fin de practicar un reconocimiento del terreno donde se libró la famosa batalla entre los ejércitos de Prusia y Austria, el día 6 de mayo de 1757 [...]. De aquí pasamos las aldeas de Biechvitz, Bohmischbrod, Planany (Běchovice, Český Brod, Plaňany) y llegamos a Kolin antes de las cuatro p. m. [...] y en la mañana tomamos caballos y un guía para examinar el terreno sobre el cual se libró la famosa batalla entre el Rey y el Mariscal Daun.

Miranda, 12 de octubre (Miranda, 1981: 142) 33 :

De Kolin partimos a las seis de la mañana del día 12. Pasamos las aldeas de Chaslau (Čáslav), Jenikov (Jeníkov) y Steinsdorf (Jílové?). Almorzamos en un buen pueblo, Deutschbrod (Německý Brod, hoy Havlíčkův Brod), servidos por dos mujeres muy decentes y educadas. [...] Proseguimos a Stekjen (Štěkeň) e Iglau (Jihlava). Ahora dejamos el reino de Bohemia, donde la superstición parece predominar mucho. Toda la región está muy cultivada, pero las aldeas son pobres y los habitantes tan miserables como puede tenerlos la astucia clerical. Los caminos, después de atravesar los montes que separan a este reino del Electorado de Sajonia, están bien hechos, igual a los ingleses y llamados Camino Imperial. [...] Nos vimos obligados a detenernos en Jglau, la primera ciudad de la frontera de Moravia, por falta de caballos.

Miranda, 13 de octubre (Miranda, 1981: 143):

A las cuatro del día 13 salimos de Iglau (Jihlava), que es una aldea mediocre, situada en las fronteras del Ducado de Moravia, sobre el río Iglau. [...] Pasamos Stannern (Stonařov), Schaletaw ${ }^{34}$, Budwitz (Moravské Budějovice) y Freinersdorf (Vranovská Ves), donde almorzamos. Estas aldeas son todas iguales. Llegamos a Znaim (Znojmo), una agradable y próspera ciudad sobre el Jaya (río Dyje), en la

31 En la palabra de «sobrecargado» con la que califica las esculturas del puente Carlos, se siente claramente el repudio de Miranda, en tanto que partidario de la Ilustración, ante el Barroco.

32 Como militar, Miranda se interesa por conocer los lugares de las batallas más famosas como fue la de los ejércitos de Prusia y Austria en 1757, donde Federico II fue vencido por los austriacos bajo el mando de Leopoldo Daun.

33 Una vez más, Miranda da a conocer su repudio a la Iglesia.

34 Localidad inidentificable, cuya forma alemana transcrita como Schaletaw se da exclusivamente en la Colombeia. 
frontera del Ducado de Austria. [...] Un ancho puente de madera la une a una aldea que se extiende al sur del Jaya. El terreno sobre estas márgenes es bueno y se cultiva la uva extensamente. Pasamos a Jetzelsdorf y nos alojamos bien en Hollabrunn.

\section{Conclusiones}

En la época cuando Miranda visitó Praga, esta era una metrópoli de una belleza de cuentos de hadas, de colores ricos, con iglesias, palacios, casas civiles perfectamente formadas, con jardines y verdor exuberante en los cayos del río Vltava. No olvidemos que en el curso del siglo XVIII culminó la reconstrucción barroca convirtiendo a Praga en un fenómeno espacial único. Más tarde, las ondeadas líneas barrocas vuelven a calmarse y a enderezarse. En este estado se conservó Praga, en algunos barrios por completo, como en Malá Strana, en otros, como las Ciudades Vieja y la Nueva (esta es, sin embargo, del siglo XIV, a diferencia de la Vieja, del siglo XII) por lo menos parcialmente, de modo que el testimonio de Miranda no solo sigue siendo válido, sino incluso puede ser inspirativo para cualquier visitante, venezolano o no, que quiera emprender la gira a la capital de la República Checa. Así también entenderemos mejor la exclamación de Denzil Romero en su libro Gran Tour, en el que reconstruye la estancia de Miranda en Praga: Estás en otra ciudad. O quizás, en la misma ciudad; pero fuera del tiempo (Romero, 1987: 26).

La visita de Miranda, relatada en Colombeia, no es la única huella del prócer de la Independencia de Venezuela en Bohemia. Ya poco después tenemos testimonio de su presencia a través de sus libros, ante todo la correspondencia, publicada en París en 1793 (Correspondance Du Général Miranda Avec Le Général Dumourier) que está en sendos ejemplares en las bibliotecas palaciegas checas -en el de los Mladá Vožice y el de Konopiště- que indica el interés que ha habido en el héroe de la gesta de la Independencia americana ${ }^{35}$. Y también está en las bibliotecas checas un libro predilecto por Miranda, el de Gumilla ${ }^{36}$.

La gran obra Colombeia no quedó sin ecos; como ya hemos observado, uno de los escritores venezolanos de la segunda mitad del s. XX, Denzil Romero, tomó de ella las bases para una novela histórica llena de imaginación, que reconstruye, de manera imaginaria, casi a nivel del realismo mágico, este gran viaje ilustrado del peregrino del siglo XVIII (Romero, 1987: 321) ${ }^{37}$. En sus líneas, dedicadas a Miranda, también exaltó en más de una oportunidad el brillo del ambiente de la ciudad encantada que para él es Praga. Romero aprovechó su estancia en Praga para trazar, con conocimiento del ambiente y de la historia, con algunos detalles más bien intencionalmente retorcidos, para aumentar lo mágico del ambiente, un recorrido apócrifo del héroe, cuya pista sigue por Praga. Según esta versión fantástico-mágica, Miranda se encuentra con personajes como Faust, Paracelso y Cornelius Agrippa, y con ellos recorre los lugares más destacados y enigmáticos.

Con esto queda demostrada, además, la influencia que ejerce la lectura, aunque en clave fantasiosa, del gran clásico venezolano del siglo XVIII en un hombre sensible del final del siglo XX.

35 Miranda (1793), Mladá Vožice, nr. inv. 7C 2078, Konopiště, nr. inv. 4-17. El Museo Nacional solo tiene dos libros ya del siglo XX: Miranda (1928), the Spanish text edited with introduction and notes by William Spence Robertson, nr. inv. 61 B 195; y el segundo: Siso Martínez (1969), nr. inv. 172 A 382.

36 Uslar Pietri (1979: XVIII). El texto de Gumilla (1758), se encuentra en la biblioteca del palacio de Březnice (solo se ha conservado el primer tomo, $n^{\circ} 161$ ), en el Castillo de Křivoklát (nr. inv. XII.c 42 /9.2679.269) y el tercer ejemplar en el Museo Nacional de Praga (nr. inv. 45 E 32, Tomo I. -III. y 48 G 14, igual los tres tomos).

37 No podemos pasar por alto que el autor cierra su libro con la fecha y lugar entre Caracas, noviembre de 1982 y Praga, junio de 1986. 
92 Pavel Štěpánek Francisco de Miranda en Praga, una visita venezolana a la Praga de la llustración...

Así, los lugares que Miranda apenas menciona aunque debió haberlos recorrido, los reconstruye Romero doscientos años más tarde con abundantes detalles. Sin embargo, el diario de Miranda no es una guía de la ciudad, sino un apunte de impresiones que le produjo la ciudad, los monumentos, las aldeas, el paisaje y la gente, así como los eventos históricos del país. Lo mismo pasa con la reinterpretación de Denzil Romero. A él no se le ha escapado, al reinterpretar la Colombeia, el aspecto subjetivo de la descripción del gran racionalista que fue Miranda; aunque al escritor le sirven varios hechos de la historia (y quizás algunas incorrecciones, posiblemente intencionadas) solo como un trampolín para intensificar y aumentar la atmósfera mágica de Praga y para situar la novela «fuera del tiempo» (Romero, 1987: 343).

El texto se ha creado con el apoyo del Ministerio de Educación, Juventud y Deportes, subvención del proyecto IGA_FF_2015_025 (De la Edad Media a la actualidad. Estudio sobre arte en las tierras checas) $)^{38}$. 


\section{Bibliografía}

$\checkmark$ AA. VV. (1833). Dictator von Columbia. Leipzig: Bibliothek parlamentarischer Beredsamkeit.

> AA. VV. (1963). Československý hudební slovník osob a institucí. I. Praga: Státní hudební nakladatelství.

$\checkmark$ BELLO, Andrés (1908). Gramática de la lengua castellana destinada al uso de los americanos. París: R. Roger y F. Chervoviz, 1908.

\ Archivo del General Miranda/Viajes/Diarios/1750-1785/. Tomo I. (1925). Caracas: Editorial Sur-América.

$\checkmark \quad$ BLAŽEK, Vlastimil (1937). Mozart 1787-1937 Praha. Praha: V. Neubert.

\ CAstillo Didier, Miguel (1991). Miranda y la senda de Bello. Caracas: Ediciones de la Presidencia de la República.

\ CERVERA, César; ESLAVA GALÁN, Juan (2019). «Los mismos que silenciaron y orillaron a los indios quieren ser ahora sus heraldos». ABC Cultural, 23-07-2019. https://www.abc.es/cultura/cultural/abci-juan-eslava-galan-mismos-silenciaron-y-orillaron-indios-quieren-ahora-heraldos-201907210116_noticia.html [12-09-2019].

У DVOŘÁKovÁ, Vlasta (1986). «Osvícenci a romantikové (Ilustrados y románticos)». In: Kapitoly z českého dějepisu umění. I. Praha: Odeon.

У GRIGULIEVICH LAVRETSKI, José (1974). Miranda: la vida ilustre del Precursor de la Independencia de América Latina. Caracas: Contraloría General de la República.

\ GUMiLla, José (1758). Histoire Naturelle, civille et géographique de l'Orénoque. Et les princiaples Rivières qui s'y jettent... Par le P. Joseph Gumilla, de la Compagnie de Jesus. Avignon: Jean Moss.

У LAKosILovÁ Jarmila; PASÁKOvÁ Jana (sin fecha). Prague architecture in End-of-18th-Century Engravings. Praha: Škodaexport, Foreign Trade Corporation.

$\searrow \quad$ LOVERA DE SOLA , R. J. (1994). «El “Diario" de Francisco Miranda». Diario de Caracas, 29-3-1994.

$\checkmark$ MAYO, Linda (1965). «Miss Adams in Love». American Heritage 16.2, sin p.

$\checkmark \quad$ MIRANDA, Francisco de (1928). The Diary of Francisco de Miranda's Tour of the United States 1783-1784. Notes by William Spence Robertson. New York: The Hispanic Society of America.

У MIRANDA, Francisco de (1981). Colombeia. El Viajero Ilustrado, 1785-1786. Tomo IV. 2 ed. Caracas: Ediciones de la Presidencia de la República.

У MIRANDA, Francisco de (1793). Correspondance Du Général Miranda Avec Le Général Dumourier. Paris: Barrois l'Aîné.

У PICón SALAS, Mariano (1976). Comprensión de Venezuela. Caracas: Monte Avila Editores (ed. original 1948).

\ PINEDA, Rafael (1986). Francisco de Miranda, primer crítico del arte. Los Teques: Biblioteca de Autores y Temas mirandinos.

\ POLIŠENSKÝ, Josef (1976a). «Precursor de la Independencia de América Latina en Praga y Bratislava». Archiv orientální, 44, pp. 326-327.

ע POLIŠENSKÝ, Josef (1976b). «Předchůdce nezávislosti Latinské Ameriky v Praze a v Bratislavě». Strahovská knihovna 11.8 .

У POLIŠEnSKÝ, Josef (1988). Alma Mater Carolina Pragensis. Výbor svědectví cizích návštěvníků. Praga: Universita Karlova.

У PUjMANOVÁ, Olga (1986). Italské a renesanční obrazyv československých sbírkách. Praha: Národní galerie.

$\checkmark$ ROBERTSON, William S. (1982). La Vida de Miranda. Caracas: Banco Industrial de Venezuela.

\ RODRÍGUEZ DE ALONSO, Josefina (1974). Le siècle des Lumières, conté par Francisco de Miranda. Paris: France-Empire.

У RODRÍGUEZ DE ALONSO Josefina (1978). El siglo de las luces, visto por Francisco de Miranda. Caracas: Ediciones de la Presidencia de la República.

У ROMERo, Denzil (1987). Grand Tour. Epistasis. Caracas / Barcelona: Alfadil.

$\checkmark \quad$ RUIZ, Luis Alberto (1977). Diccionario de Sectas y Herejías. Buenos Aires: Claridad.

$\checkmark$ SAlCEdo-bastardo, José Luis (1988). «Miranda, Francisco de». In: Diccionario de Historia de Venezuela. Caracas: Fundación Polar. 
94 Pavel Štěpánek Francisco de Miranda en Praga, una visita venezolana a la Praga de la llustración...

У SISo MARTínEZ, José Manuel (1969). El paisaje histórico de Don Francisco de Miranda. Caracas: Ediciones del Ministerio de Educación.

У ŠTĚPÁNEK, Pavel (1994). Miranda en Praga. (La Praga de Miranda). Caracas: Asociación checo-venezolana, Embajada de la República Checa.

У ŠTĚPÁNEK, Pavel (2004). Cruces de la cultura checa y la venezolana. Olomouc: Univerzita Palackého.

\ USLAR PIETRI, Arturo (1979). Los libros de Miranda. Caracas: La Casa de Bello.

У USLAR PIETRI, Arturo (1981). Oraciones para despertar. Caracas: Monte Ávila.

У Vort, Petr (1990). Pražské Klementinum. Praha: Národní knihovna ČR.

\section{Pavel Štěpánek}

Katedra dějin umění

Filozofická fakulta

Univerzita Palackého

Univerzitní 3

77180 OLOMOUC

República Checa 